\title{
Testing the unique amplification event and the worldwide migration hypothesis of insecticide resistance genes with sequence data
}

\author{
THOMAS GUILLEMAUD*, SERENA ROOKER†, NICOLE PASTEUR \& MICHEL \\ RAYMOND \\ Institut des Sciences de rEvolution, Laboratoire Génétique et Environnement (C.C. 065), URA CNRS 327, Université \\ de Montpellier II, F-34095 Montpellier, France
}

\begin{abstract}
In the mosquito Culex pipiens, over-production of esterases is a common insecticide resistance mechanism. Different alleles at the esterase $A$ and $B$ loci are known to occur in natural populations, as shown by enzyme electrophoresis and RFLP studies on the esterase $B$ locus. Here we analyse the variability of the esterase $A$ locus at the nucleotide level in mosquitoes possessing or lacking over-produced esterase A. A surprisingly high level of nucleotide polymorphism is found in coding and noncoding regions, and the extent of polymorphism detected is higher than that previously described for the most polymorphic loci in Drosophila. We also show that eight strains from different localities (Africa, America, Asia) that possess the over-produced esterase A2 share the same nucleotide sequence at the esterase $A$ locus, strongly supporting the evolutionary scenario of a unique event of amplification of this gene followed by dispersal through migration rather than the occurrence of multiple independent mutational events of the gene.
\end{abstract}

Keywords: Culex pipiens, esterases, evolution, nucleotide polymorphism.

\section{Introduction}

The wide use of organic insecticides to control medically important pest species has been a powerful agent of selection in natural populations of many insect species which have developed various degrees of resistance (Georghiou \& Lagunes-Tejeda, 1991). In a few species, such as the mosquito Culex pipiens, it is possible to identify each gene conferring resistance to organophosphorous insecticides in single individuals.

This mosquito, common in temperate and tropical countries, is subjected to insecticide control in many places. Worldwide surveys of resistance to organophosphorous insecticides have disclosed that only three loci have developed major resistance alleles (Pasteur et al., 1981; Wirth et al., 1990; Georghiou, 1992; Poirié et al., 1992). The first two loci, Est-2 (or

\footnotetext{
*Correspondence.

†Present address: Department of Molecular Genetics, National Heart and Lung Institute, Heart Science Centre, Harefield Hospital, Middlesex, U.K.
}

esterase B) and Est-3 (or esterase A), code for detoxifying carboxylester hydrolases, and resistant alleles correspond to an esterase over-production (Fournier et al., 1987; Mouchès et al., 1987; Poirié et al., 1992). Five distinct electromorphs have been described so far at the esterase $B$ locus and three at the esterase $A$ locus (Pasteur et al., 1981, 1984; Raymond et al., 1989; Georghiou, 1992; Poirié et al., 1992; Xu et al., 1994; Vaughan et al., 1995). The over-production of esterase is the result of gene amplification (Mouchès et al., 1986; Raymond et al., 1989; Poirié et al., 1992; Vaughan \& Hemingway, 1995) and/or gene regulation (Rooker et al., 1996). In some situations, both esterase $A$ and $B$ loci are co-amplified, which explains the tight statistical association of some electromorphs, like A2 and B2 (Rooker et al., 1996). The third locus, Ace, codes the acetylcholinesterase (insecticide target), and insensitive alleles have been reported in various places (Raymond et al., 1986; Bourguet et al., 1996) but it is not known how many resistant $A c e$ alleles have occurred independently.

Restriction maps of the DNA within and around the esterase $B$ structural gene can be built, in suscep- 
tible mosquitoes with a single copy of the gene, as well as in mosquitoes with an amplified haplotype (the amplicon is larger than the DNA area mapped). When such maps are compared, large differences are observed. For example, two maps from Californian mosquitoes, one of a nonamplified allele and the other of an amplified allele, have only 21 per cent of their restriction sites in common (Raymond et al., 1991). However, when strains with the B2 electromorph are compared, restriction maps are strictly identical, independently of the geographical origins of the insects considered (Raymond et al., 1991). A similar situation is found for the B1 electromorph: mosquitoes from various localities within the Americas and China possess the same restriction map (Qiao \& Raymond, 1995). A large part of the polymorphism detected by restriction enzymes around the esterase B structural gene is probably neutral. The similarity of the restriction maps of all B1 (or all B2) haplotypes from diverse and distant geographical areas indicates that all B1 (or all B2) alleles are identical by descent. There are two possible events to explain this: either each allele was first amplified in a particular place, and has then spread, or it has first spread and then been independently amplified in various places.

The first scenario was proposed by Raymond et al. (1991) and Qiao \& Raymond (1995), based on the argument that the probability of independently amplifying the same allele many times is very low. This is true if the polymorphism of esterase haplotypes in susceptible populations is large (Raymond et al., 1995). In addition, the selective advantage provided by the amplification itself in organophosphorous treated places promotes its spread. The multiple and independent amplification of B2 has been favours: by Hemingway et al. (1993) and Ketterman et al. (1993), based on variations in the kinetics of the over-produced esterases studied on partially purified enzymes.

Recent data indicate that the RFLP at the $3^{\prime}$ flanking sequence of the esterase $B$ gene and the electrophoretic polymorphism at both esterase $A$ and $B$ loci is large in two susceptible mosquito samples from Europe (Raymond et al., 1995). These results are consistent with the migration hypothesis. So far, no molecular data at the DNA level have been published to test the unique origin and the migration hypothesis for the esterase $A$ locus.

We describe here nucleotide variations for the esterase $A$ locus in Culex pipiens from alleles sampled from various parts of the world. Both nonamplified and amplified esterase $A$ alleles are considered, with the aim of comparing the nucleotide variation assoc- iated with the widespread A2 variant versus those detected within the nonamplified esterase $A$ gene. In addition, the contrasting levels of polymorphism and divergence at synonymous and nonsynonymous sites are analysed to provide some insight into the importance of neutral versus selective forces operating at the esterase $A$ locus.

\section{Materials and methods}

\section{Mosquito strains}

Three types of mosquitoes were used as follows. First, nine strains lacking an over-produced esterase A: BRUGES-A and BRUGES-B, two susceptible isofemale and inbred strains from Belgium (Raymond et al., 1995); MSE, a laboratory strain resistant to organophophorous and carbamate insecticides possessing an insensitive $\mathrm{AChE}$, collected in 1979 near Montpellier, southern France (Raymond et al., 1986; Bourguet et al., 1996); TEM-R, a strain resistant to OP from California (Georghiou \& Pasteur, 1978), homozygous for the presence of esterase B1 (Raymond et al., 1993); TRANS-P, a laboratory strain resistant to trans-permethrin from California (Priester \& Georghiou, 1978); EVORA, an isofemale strain derived from larvae collected in November 1991 from sewage in downtown Evora, Portugal, and maintained by sib-mating during more than ten generations; EDIT, an isofemale strain derived from a cross between SUTTER-YUBA, a strain from Sutter-Yuba, California (Qiao \& Raymond, 1995), and S-LAB (Georghiou et al., 1966), and made homozygous for a single level of amplification of the B1 allele (N. Pasteur et al., unpublished data); ACHE-R, a strain from Cyprus displaying an insensitive acetylcholinesterase, collected in 1987 (Wirth \& Georghiou, 1996); KOCHI, a strain resistant to Bacillus sphaericus, originating from Kochi, India (Rao et al., 1995). Secondly, eight strains selected for homozygosity for the presence of the highly active A2-B2 esterases: SELAX, the A2-B2 reference strain, derived from a 1984 sample from California (Raymond et al., 1987); BOUAKE, collected in February 1986 from Bouaké, Ivory Coast (Magnin et al., 1988); SUPERCAR collected in March 1994 from Bouaké, Ivory Coast, and provided by F. Chandre (ORSTOM, Montpellier, France); LAHORE, from Pakistan (BeyssatArnaouty, 1989); BRAZZA, from Congo (Beyssat-Arnaouty, 1989); BED, a strain collected in January 1991 from Johannesburg, South Africa, and provided by A. J. Cornel (The South African Institute for Medical Research, South Africa); THAI, an 
isofemale strain from Bangok, Thailand, collected in 1991; MOOREA, a strain collected in October 1990 in Moorea, French Polynesia (Pasteur et al., 1995). Thirdly, three strains homozygous for the presence of the over-produced esterases A4 and B4 (VIM, from Montpellier, southern France), A5 and B5 (CYPRUS from Cyprus) and A1 (BARRIOL, from Arles, southern France) (Poirié et al., 1992; Chevillon et al., 1995).

\section{Sequencing of esterase}

Genomic DNA from single adults was obtained according to Raymond \& Marquine (1994). The DNA was suspended in $10 \mu \mathrm{L}$ of T.E. buffer (Tris $\mathrm{HCl}, \mathrm{pH} 8.0,10 \mathrm{~mm}$, EDTA $1 \mathrm{~mm}$ ) and used for PCR without further dilution. PCR primers were designed from the A2 cDNA sequence of the strain PelRR (Vaughan \& Hemingway, 1995), to amplify specifically esterase $A$ genes. The primer set was 5'-GCAACGGGGGTCGATTACTAC-3' and 5'-ACTTCATTCGTTCCTGCTCCG-3'. The $100 \mu \mathrm{L}$ PCR reaction contained $0.25 \mu \mathrm{L}$ of DNA, $2 \mu \mathrm{M}$ of each primer, $1.25 \mathrm{~mm}$ of each dNTP, $1.5 \mathrm{~mm} \mathrm{MgCl}_{2}$ and 2.5 units of Taq polymerase (Goldstar Polymerase, Eurogentec, Louvain-la-Neuve, Belgium) in $1 \times$ enzyme buffer supplied by the manufacturer. The reaction mixture was overlaid with mineral oil and heated in a Crocodile thermocycler (Appligene, Pleasenton, CA, USA) at $95^{\circ} \mathrm{C}$ for 4 min followed by 30 cycles of $95^{\circ} \mathrm{C}$ for $1 \mathrm{~min}, 60^{\circ} \mathrm{C}$ for $1.50 \mathrm{~min}, 72^{\circ} \mathrm{C}$ for $2 \mathrm{~min}$. A final extension step was included at $72^{\circ} \mathrm{C}$ for $10 \mathrm{~min}$. A $5 \mu \mathrm{L}$ aliquot was removed for agarose gel electrophoresis and the PCR product was visualized by ethidium bromide staining. PCR products were sequenced following a direct method (Rousset et al., 1992), using individual primers to direct DNA synthesis. The primers used to sequence the introns were, with the position in the PelRR A2 esterase sequence of Vaughan \& Hemingway (1995), 5'-GCAACGGGGGTCGATTACTAC-3' (67-87), 5'-AAACCGTGGACGGAACCGTTG-3' (157-177), 5'-GAGAGGATCTAGTGGGGTGGAG-3' (336357), 5'-TACCACATGGTGTCGGACCT-3' (595614), 5'-GATTCGGACACCTACAACCACT-3' (1270-1291). The nucleotide in italics of primer 336-357 corresponds to a A in the PellRR A2 sequence. DNA sequences were manually aligned by minimizing the number of mismatches and gaps assumed in the sequence.

\section{Statistics}

The number of synonymous and nonsynonymous sites per codon was estimated following the method of Nei \& Gojobori (1986). For computing nucleotide diversity and the number of polymorphic sites, each single or multiple insertion/deletion was considered as one mutation. An unbiased estimate of the $P$ value of the exact Fisher test on an $\mathrm{R} \times \mathrm{C}$ contingency table was computed using a Markov chain method. The Markov chain was set to at least $10^{6}$ steps, and 1000 steps of dememorization in order to obtain standard error estimates below 0.005 (see Guo \& Thompson (1992) for details). The sTRUC program was used for these computations (Raymond \& Rousset, 1995).

\section{Results}

\section{Sequences and variability of A esterase genes}

The length of the PCR product obtained from genomic DNA of each strain was around $1800 \mathrm{bp}$, whereas the corresponding cDNA length is about $1520 \mathrm{bp}$. The major part of the esterase $A$ gene (1755 bp or 84.2 per cent of the gene) was sequenced from strains displaying no over-produced esterase (MSE), and over-produced esterases A1 (BARRIOL), A5 (CYPRUS), A2 (SELAX) and A4 (VIM). Six short introns (named I to VI) were found in the five sequences, respectively at positions $142,280,430$, 823,1168 and 1423 of the cDNA A2 esterase sequence (Vaughan \& Hemingway, 1995).

The alignments of the five sequences show a high degree of variability either in the exons or in the introns as indicated (Table 1) by the percentage of segregating sites (at least 8.7 per cent and 21.4 per cent, respectively) and the nucleotide diversity per site (at least 0.038 and 0.088 , respectively). The polymorphism detected in the coding regions consists only in nucleotide substrtitions, whereas introns I, II, V and VI present various levels of polymorphism which involve single or multiple-bp deletion/insertion (Fig. 1).

The level of variability measured by the percentage of polymorphic nucleotide sites is higher in introns than in exons $(27.8$ per cent vs. 11.3 per cent; Fisher's exact test, $\left.P<10^{-5}\right)$. Among the six introns, the hypothesis of homogeneity of polymorphic and nonpolymorphic sites is not rejected (Fisher's exact test, $P=0.11$ ). The same result is found for the six exons (Fisher's exact test, $P=0.56$ ), so that the global nucleotide polymorphism of coding or noncoding regions does not appear to be concentrated in a few areas. There are between seven and 12 differences in amino acid composition between pairs of the five coding sequences (Fig. 2). This high degree of polymorphism in coding sequences is also 
Table 1 Nucleotide polymorphism at the esterase $A$ locus of $C$ Culex pipiens from the partial sequences of BARRIOL, SELAX, CYPRUS, VIM and MSE

\begin{tabular}{|c|c|c|c|c|}
\hline & $\begin{array}{l}\text { Number } \\
\text { of bp }\end{array}$ & $\begin{array}{c}\% \text { of } \\
\text { segregating } \\
\text { sites }\end{array}$ & $\pi$ & $\pi \mathrm{ns} / \pi \mathrm{s}$ \\
\hline Intron I & 62 & 24.2 & 0.145 & \\
\hline Exon II & 138 & 8.7 & 0.038 & 0.047 \\
\hline Synonymous & 26 & 38.5 & 0.15 & \\
\hline Nonsynonymous & 112 & 1.8 & 0.007 & \\
\hline Intron II & 74 & 21.6 & 0.088 & \\
\hline Exon III & 150 & 12.7 & 0.62 & 0.053 \\
\hline Synonymous & 30 & 53.3 & 0.226 & \\
\hline Nonsynonymous & 120 & 2.5 & 0.012 & \\
\hline Intron III & 56 & 21.4 & 0.093 & \\
\hline Exon IV & 393 & 10.4 & 0.05 & 0.056 \\
\hline Synonymous & 89 & 39.3 & 0.177 & \\
\hline Nonsynonymous & 304 & 2.0 & 0.01 & \\
\hline Intron IV & 57 & 40.4 & 0.169 & \\
\hline Exon V & 345 & 13.6 & 0.068 & 0.028 \\
\hline Synonymous & 64 & 67.2 & 0.282 & \\
\hline Nonsynonymous & 281 & 1.4 & 0.008 & \\
\hline Intron $\mathrm{V}$ & 55 & 25.5 & 0.124 & \\
\hline Exon VI & 255 & 9.8 & 0.05 & 0 \\
\hline Synonymous & 52 & 48.1 & 0.205 & \\
\hline Nonsynonymous & 203 & 0 & 0 & \\
\hline Intron VI & 56 & 35.6 & 0.186 & \\
\hline Exon VII & 114 & 12.3 & 0.053 & 0.321 \\
\hline Synonymous & 20 & 30.0 & 0.112 & \\
\hline Nonsynonymous & 94 & 8.5 & 0.036 & \\
\hline \multicolumn{5}{|l|}{ Summary } \\
\hline Coding & 1395 & 11.3 & 0.055 & 0.049 \\
\hline Synonymous & 281 & 48.0 & 0.205 & \\
\hline Nonsynonymous & 1114 & 2.1 & 0.01 & \\
\hline Noncoding & 360 & 27.8 & 0.132 & \\
\hline Total & 1755 & 14.7 & 0.071 & \\
\hline
\end{tabular}

$\pi$ refers to the nucleotide diversity per site, $\pi$ ns to the nucleotide diversity per nonsynonymous site and $\pi$ s to the nucleotide diversity per synonymous site.

measured by the nucleotide diversity per nonsynonymous site, $\pi \mathrm{ns}=0.01$. Within the coding regions, differences are found between synonymous and nonsynonymous sites. Nonsynonymous polymorphism is heterogeneously distributed between exons (Fisher's exact test, $P=8.6 \times 10^{-4}, \mathrm{SE}=1.1 \times 10^{-4}$ ): 35 per cent are in exon VII and none in exon VI.

\section{Variability of intron IV of non-over-produced esterase A genes}

We attempted to analyse the polymorphism of the esterase $A$ gene in mosquitoes lacking A esterase over-production and in strains displaying overproduced esterase $\mathrm{A} 2$ by sequencing only one intron and its partial $3^{\prime}$ flanking region because: (i) the level of variability in introns is far larger than in exons, and (ii) no apparent heterogeneity of nucleotide diversity exists between the different introns. The analysis was focused on intron IV which lacks the insertion/deletion polymorphism present in introns I, II and VI and displays a larger number of polymorphic nucleotide sites than introns III or $\mathrm{V}$. Intron IV and its $3^{\prime}$ flanking region were sequenced from single individuals of the nine strains lacking over-produced esterase A. None of the mosquitoes analysed was heterozygous, which is consistent with the theoretical low heterozygosity of these inbred strains. Both regions present a high polymorphism as each different individual sequenced shows a 


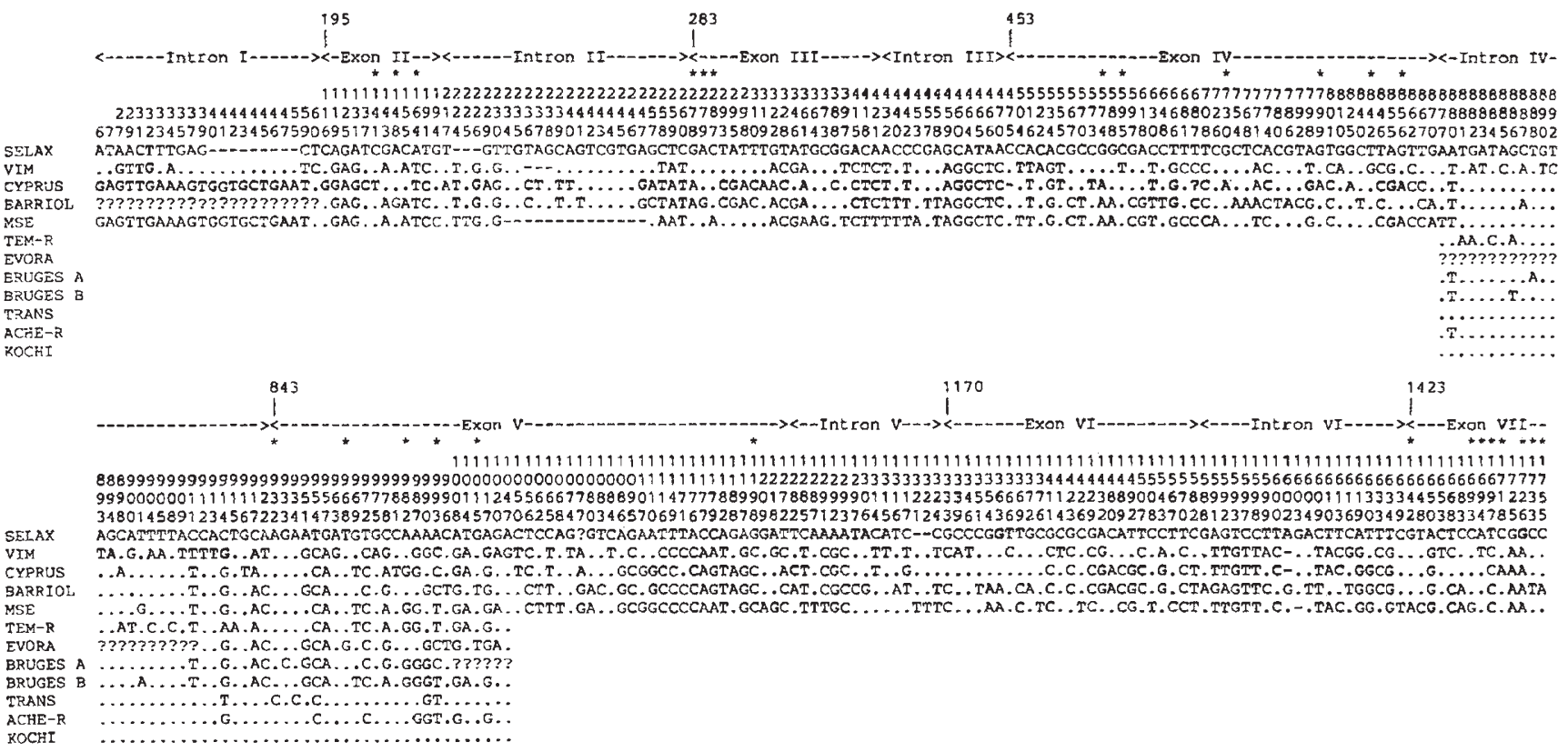

Fig. 1 Variable nucleotides at the esterase $A$ locus in Culex pipiens. All deletions including single and multiple ones are indicated by a hyphen. The positions of variable sites in the genomic sequence are given by the number above SELAX nucleotides. Position no. 1 corresponds to the $5^{\prime}$ end of intron I (position 142 in Vaughan \& Hemingway (1995)). The structure of the locus is given at the top of the figure with the corresponding numbering of the cDNA sequence from Vaughan \& Hemingway (1995). Nonsynonymous variable sites are indicated by a star above the nucleotide positions.

1112222222234444444 23452370122344512445556 83707492618947567452574

\begin{tabular}{|c|c|}
\hline SELAX & NRDQVPVAVVIVIKVEVQIAAPN \\
\hline VIM & .S...S..G....N.Q.LT.T.. \\
\hline CYPRUS & .SN.I.IT.I..VN.Q. .TET.. \\
\hline BARRIOL & SSS.I........ NLQ..T.TLK \\
\hline MSE & .S.KI....I..VN.QIET.T.. \\
\hline TEM-R & $\ldots$ VN \\
\hline EDIT & $\ldots \mathrm{VN}$. \\
\hline EVORA & . G.NL \\
\hline BRUGES A & . . VN? \\
\hline BRUGES B & . VN. \\
\hline TRANS & L. .N. \\
\hline $\mathrm{ACHE}-\mathrm{R}$ & $\ldots N$. \\
\hline $\mathrm{KOCHI}$ & $\ldots$ \\
\hline
\end{tabular}

Fig. 2 Variable amino acids at the esterase $A$ locus in Culex pipiens. The positions of variable sites are given by the number above SELAX nucleotides. The first position corresponds to the 5' end of Exon II.

different allele at this locus, the only exception being two Californian mosquitoes from the strains EDIT and TEM-R. These two laboratory strains containing a single over-produced esterase (B1) were collected 14 years apart. The association of the same esterase
$A$ allele with the amplified esterase $B 1$ has been maintained by linkage disequilibrium. In the present study, EDIT and TEM-R cannot be considered as randomly chosen from mosquitoes lacking overproduced esterase $\mathrm{A}$, and thus, in the following, EDIT will not be considered further.

The variability observed in intron IV and its $3^{\prime}$ flanking region in the strains lacking over-produced esterases (Table 2) is of the same order of magnitude as among strains with over-produced esterases A1, A2, A4 and A5. Moreover, in the short coding region sequenced for all strains, no particular site is shared only by mosquitoes possessing an overproduced esterase A. Thus, on this restricted dataset, there is no evidence for a relationship between the nucleotide polymorphism at the esterase $A$ locus and the over-production of the corresponding esterase.

\section{Variability of intron IV of A2 esterase genes}

In contrast, the eight sequences of intron IV and its $3^{\prime}$ flanking region from mosquitoes with overproduced esterases $\mathrm{A} 2$ and $\mathrm{B} 2$, and originating from various countries (Ivory Coast, Congo, South Africa, Thailand, French Polynesia, USA and Pakistan) are strictly identical, even in the noncoding region. 
Table 2 Nucieotide polymorphism at intron IV plus its $3^{\prime}$ flanking region from the sequences of Culex pipiens lacking over-produced esterase A and BARRIOL, CYPRUS, SELAX and VIM

\begin{tabular}{|c|c|c|c|c|}
\hline & $\begin{array}{c}\text { Number } \\
\text { of bp }\end{array}$ & $\begin{array}{c}\% \text { of } \\
\text { segregating } \\
\text { sites }\end{array}$ & $\pi$ & $\pi \mathrm{ns} / \pi \mathrm{s}$ \\
\hline Intron IV & 57 & 40 & 0.169 & \\
\hline Exon V (5' end) & 117 & 20.5 & 0.079 & 0.069 \\
\hline Synonymous & 19 & 94.7 & 0.301 & \\
\hline Nonsynonymous & 98 & 6.1 & 0.021 & \\
\hline
\end{tabular}

$\pi$ refers to the nucleotide diversity per site, $\pi$ ns to the nucleotide diversity per nonsynonymous site and $\pi$ s to the nucleotide diversity per synonymous site.

\section{Discussion}

\section{A high nucleotide polymorphism}

The sequences of 84.2 per cent of the esterase $A$ structural gene from four laboratory strains displaying over-produced esterases A1, A2, A4 and A5 (BARRIOL, SELAX, VIM and CYPRUS) and from one with no over-produced esterase (MSE) show a high degree of variability at the nucleotide level. This result is not biased by the particular choice of strains displaying over-produced esterases because the partial sequences of the eight strains lacking over-produced esterase confirmed this tendency.

The nucleotide diversity found at the esterase $A$ locus is one of the highest thus far described. In Drosophila pseudoobscura, the most polymorphic loci are $A d h$ (Schaeffer \& Miller, 1992), Xdh (Riley et al., 1992) and esterase 5-B (Veuille \& King, 1995), and the nucleotide diversities reported $(\pi=0.015$, $\pi=0.012$ and $\pi=0.012$, respectively) are about five times lower than the value estimated for esterase $A$ in Culex pipiens $(\pi=0.071)$.

The relatively low number of nonsynonymous compared with synonymous substitutions at the esterase $A$ locus in Culex pipiens suggests that purifying selection might eliminate a large part of the mutations modifying amino acids sequences. This is true for strains with $(\pi \mathrm{ns} / \pi \mathrm{s}=0.049)$ or without $(\pi \mathrm{ns} / \pi \mathrm{s}=0.099) \quad$ over-produced esterase A. This indicates that esterases A might have an important function, which could be insecticide resistance for alleles in mosquitoes displaying over-produced esterases. For strains lacking over-produced esterase, this function is still unknown as is also the case for most esterases (Aldridge, 1993).
The values of nucleotide diversity at nonsynonymous sites $(\pi \mathrm{ns}=0.01$ for over-produced and $\pi \mathrm{ns}=0.028$ for non-over-produced esterases) which are almost twice higher than the values obtained in the three last examples of Drosophila pseudoobscura sequences are in agreement with the level of polymorphism observed in allozyme analyses: 18 different electromorphs were observed in a sample of 74 mosquitoes from France and 16 electromorphs in 50 mosquitoes from England (Raymond et al., 1995).

The high level of diversity of the esterase $A$ gene indicates either a high mutation rate in this DNA region (local phenomenon) or the existence of an important effective population size in Culex pipiens (global phenomenon). The study of nucleotide diversity in other unlinked genes will allow us to discriminate among these possibilities, although ecological data do indicate that population sizes are relatively large (e.g. Bates, 1949; Chevillon, 1994). A test for departure from the neutral hypothesis, e.g. the HKA test which involves the comparison of the nucleotide diversity within and between species (Hudson et al., 1987), would allow us to determine whether selection is responsible for the large number of different alleles found at this locus.

\section{The unique amplification event and the migration hypothesis}

The eight strains displaying over-produced esterases A2 and B2 and originating from Africa, North America, Eastern and Western Asia, shared the same allele at the esterase $A$ locus. Under the multiple amplification hypothesis, the probability of obtaining eight times the amplification of this allele by randomly sampling within a gametic pool characterized by $\pi=0.13$ (the value of the nucleotide diversity for intron IV and its $3^{\prime}$ flanking region for all the strains studied here except those displaying A2 esterase) is lower than $10^{-10}$. The multiple amplification hypothesis is not supported by the present data, which are consistent with the migration hypothesis of the same amplified A2 allele. In addition, as $\mathrm{A} 2$ and $\mathrm{B} 2$ structural genes belong to the same amplicon, the A2-B2 association is probably the result of only one amplification event (Rooker $e t$ al., 1996).

This migration hypothesis is based on: (i) the existence of a large neutral polymorphism in susceptible mosquitoes, and (ii) the presence of the same amplified allele in populations from distant geographical areas. The first point has been documented at the protein level for both esterase $A$ and $B$ 
loci and indirectly at the DNA level by RFLP studies on the $B$ locus region (Raymond et al., 1995). The second point has been addressed at the DNA level only by RFLP studies (Raymond et al., 1991; Qiao \& Raymond, 1995). The nucleotide data at the esterase $A$ locus of this study are consistent with both points, as the polymorphism found in alleles of non-over-produced esterases is one of the largest thus far described, and all A2 alleles display exactly the same sequence.

In addition, there is direct (Highton \& Van Someren, 1970) and indirect (Chevillon et al., 1995; Pasteur et al., 1995) evidence of large-scale migration of this mosquito by passive transportation by humans, and the presence of one female with A2-B2 in an aircraft has been established (Curtis \& White, 1984). The local invasion of A2-B2 in southern France has been documented: A2-B2 was first found near the international Marseille airport and seaport, and has spread within a few years in all surrounding organophosphorous-treated areas (Rivet et al., 1993).

It is worthy of note that the strain KOCHI displays a sequence similar to those found in. the strains with amplified A2, although this strain does not possess over-produced esterases (unpublished data). This can be explained by at least two alternative hypotheses. First, the level of esterase A2 over-production is low and was not detectable by classical allozymic electrophoresis. Secondly, this strain possesses the allele that was shared by the susceptible ancestors prior to the amplification event. This latter hypothesis seems to be the more likely: the B esterase detected by starch gel electrophoresis is different from B2 (which is always associated with A2 when A2 is amplified). Further work is needed on this aspect.

The number of independent amplification events at the esterase $A$ and $B$ loci could not be estimated easily by just counting the number of over-produced electromorphs. First, because the esterase $A$ and $B$ loci could be amplified simultaneously, as are A2 and B2 (Rooker et al., 1996) and probably the associated A4 and B4, and A5 and B5 (T. Guillemaud et al., unpublished data), so that only one amplification event is responsible for the presence of the two electromorphs. Secondly, because an esterase overproduction is not necessarily the result of gene amplification, as for the over-production of esterase A1 owing to gene regulation (Rooker et al., 1996). Thirdly, because the same electromorph could correspond to distinct alleles, as exemplified by B4 and B5 (Poirié et al., 1992), and B1 and B8 (Vaughan et al., 1995).

(C) The Genetical Society of Great Britain, Heredity, 77, 535-543.
The present study illustrates this last point because the electrophoretically indistinguishable esterases A4 (strain VIM) and A5 (strain CYPRUS) originating from France and Cyprus present two different coding and noncoding sequences and thus correspond to two distinct alleles. In addition, there are ten amino acid differences between the A4 and A5 sequences, which is not different from any two sequence pairs drawn at random among pairs of complete sequences (between seven and 12 amino acid differences), indicating that the A4 and A5 sequences are not particularly related. These data confirm the hypothesis that these esterases were different because of their close association with, respectively, esterases B4 and B5 (Poirié et al., 1992).

Taking into account protein and DNA work published so far, the number of independent amplification events at both esterase $A$ and $B$ loci is between five and ten. The imprecision comes from the fact that a thorough checking has not been performed for all known over-produced esterases. This number corresponds to amplification events which have spread geographically because of the advantage they give in insecticide treated areas, and are therefore at high frequencies and easily detected. A more thorough sampling will probably detect additional events which either are still geographically restricted or at a low frequency, so that the above estimates should be understood as a minimum figure. Each known amplification event has spread geographically, sometimes across continents like A2-B2 (Raymond et al., 1991) and B1 (Qiao \& Raymond, 1995), sometimes only in a restricted area like A4-B4 in the western Mediterranean (Poirié et al., 1992), A5-B5 in the eastern Mediterranean (Poirié et al., 1992) and B8 in the northern Carribeans (Vaughan et al., 1995). This relatively low number of independent amplification events, inventoried on a world scale for a pest species with large population sizes, indicates that advantageous mutations (i.e. any molecular events generating a gene amplification at these loci) could be limiting. Once an amplification has occurred, it could apparently spread easily and invade the mosquito genome. Clearly, migration can not be ignored as a driving force in studies and monitoring of insecticide treated populations of the mosquito Culex pipiens.

\section{Acknowledgments}

We thank C. Bernard and G. Pistre for technical assistance and D. Bourguet and J. Lagnel for helpful 
comments and discussions. This work was financed in part by a GDR 1105 du programme Environnement, Vie \& Sociétés du CNRS and a CEE grant (No ERBCHRXCT930172). S.R. benefited from a CEE fellowship and T.G. from a MESR fellowship (no. 94137). This is contribution ISEM 96.105 of the Institut des Sciences de l'Evolution (URA CNRS 327).

\section{References}

ALDRIDGE, W. N. 1993. The esterases: perspective and problems. Chem.-Biol. Interact., 87, 5-13.

BATES, M. 1949. The Natural History of Mosquitoes. Macmillan, New York.

Beyssat-ARnaouty, v. 1989. Etude Biochimique et Moléculaire de la Résistance aux Insecticides Organophosphorés, chez le Moustique du Complexe Culex pipiens $L$. Thèse de Doctorat, Université de Montpellier II.

Bourguet, D., CAPElA, R. AND RAYMOND, M. 1996. An insensitive acetylcholinesterase in Culex pipiens $\mathrm{L}$. mosquitoes from Portugal. J. Econ. Entomol. (in press).

CHEvillon, C. 1994. Evolution de Mécanismes Adaptatifs: Flux Géniques, Sélection et Contre-sélection. Thése de Doctorat, Université de Montpellier II.

CheVillon, C., PASTeur, N., MARQuine, M., heyse, D. AND RAYMOND, M. 1995. Population structure and dynamics of selected genes in the mosquito Culex pipiens. Evolution, 49, 997-1007.

CURTIS, C. F. AND White, G. B. 1984. Plasmodium falciparum transmission in England: entomological data relative to cases in 1983. J. Trop. Med. Hyg., 87, 101-194.

FOURNIER, D., BRIDE, J. M., MOUCHÈS, C., RAYMOND, M., MAGNIN, M., BERGÉ, J. B. ET AL. 1987. Biochemical characterization of the esterases A1 and B1 associated with organophosphate resistance in the Culex pipiens complex. Pest. Biochem. Physiol., 27, 211-217.

GEORGHIOU, G. P. 1992. World distribution of esterases involved in organophosphate insecticide resistance in Culex mosquitoes, and methods for detection. In: Otto, D. and Weber, B. (eds) Insecticides: Mechanism of Action and Resistance, pp. 407-408. Intercept, Andover.

GeORghiou, G. P. AND LAgunes-TEJEdA, A. 1991. The Occurrence of Resistance to Pesticides in Arthropods. Food and Agriculture Organization, Rome.

GEORGHIOU, G. P. AND PASTEUR, N. 1978. Electrophoretic pattern in insecticide-resistant and susceptible mosquitoes. J. Econ. Entomol., 7, 201-205.

GEORghiou, G. P., METCALF, R. L. AND GIDDEN, F. E. 1966. Carbamate resistance in mosquitoes: selection of Culex pipiens fatigans Wied. (=Culex quinquefasciatus) for resistance to Baygon. Bull. W.H.O., 35, 691-708.

GuO, s. W. AND THOMPSON, E. A. 1992. Performing the exact test of Hardy-Weinberg proportions for multiple alleles. Biometrics, 48, 361-372.

hemingway, J., KeTterman, A. J., Karunaratne, S. H. P.
P., IAYAWARDENA, K. G. I. AND VAUGHan, A. 1993. Amplified esterases A2 and B2. Has resistance occurred once or several times? In: Widley, K. B. and Robinson, W. H. (eds) Proceedings of the First International Conference on Insect Pests in the Urban Environment, pp. 319-328. BPCC Wheatons, Exeter.

HIGHTON, R. B. AND VAN SOMEREN, C. C. 1970. The transportation of mosquitos between international airports. Bull. W.H.O., 42, 334-335.

HUDSON, R. R., KREITMAN, M. AND AGUAdÉ, M. 1987. A test of neutral molecular evolution based on nucleotide data. Genetics, 116, 153-159.

KeTterman, A., KARUNARATNE, S. H. P. P., JAYAWARDENA, K. G. I. AND HEMINGWAY, J. 1993. Qualitative change between populations of Culex quinquefasciatus in both the esterases A2 and B2 which are involved in insecticide resistance. Pest. Biochem. Physiol., 47, 142-148.

MAGNIN, M., MARBOUTIN, E. AND PASTEUR, N. 1988. Insecticide resistance in Culex quinquefasciatus (Diptera: Culicidae) in West Africa. J. Med. Entomol., 25, 99-104.

MOUCHĖS, C., PASTEUR, N., BERGÉ, J.-B., HYRIEN, O., RAYMOND, M., ROBERT DE SAINT VINCENT, B. ET AL. 1986. Amplification of an esterase gene is responsible for insecticide resistance in a California Culex mosquito. Science, 233, 778-780.

MOUChÈS, C., MAGNin, M., Bergé, J.-B., DE SILVESTRI, M., BEYSSAT, V., PASTEUR, N. AND GEORGHIOU, G. P. 1987. Overproduction of detoxifying esterases in organophosphate-resistant Culex mosquitoes and their presence in other insects. Proc. Natl. Acad. Sci. U.S.A., 84, 2113-2116.

NEI, M. AND GojoborI, T. 1986. Simple methods for estimating the number of synonymous and nonsynonymous nucleotide substitutions. Mol. Biol. Evol., 3, 418-426.

pasteur, N., ISEKI, A. AND GEORGHIOU, G. P. 1981. Genetic and biochemical studies of the highly active esterases $\mathrm{A}^{\prime}$ and $\mathrm{B}^{\prime}$ associated with organophosphate resistance in mosquitoes of the Culex pipiens complex. Biochem. Genet., 19, 909-919.

PASTEUR, N., GEORGHIOU, G. P. AND ISEK1, A. 1984. Variation in organophosphate resistance and esterase activity in Culex quinquefasciatus Say from California. Génét. Sél. Évol., 16, 271-284.

PASTEUR, N., MARQuine, M., Rousset, F., FAlllouX, A.-B., CHEVILLON, C. AND RAYMOND, M. 1995. The role of passive migration in the dispersal of resistance genes in Culex pipiens quinquefasciatus within French Polynesia. Genet. Res., 66, 139-146.

POIRIÉ, M., RAYMOND, M. AND PASTEUR, N. 1992. Identification of two distinct amplifications of the esterase $B$ locus in Culex pipiens (L.) mosquitoes from mediterranean countries. Biochem. Genet., 30, 13-26.

PRIESTER, T. M. AND GEORGHIOU, G. P. 1978. Induction of high resistance to permethrin in Culex pipiens quinquefasciatus. J. Econ. Entomol., 71, 197-200.

QIAO, C.-L. AND RAYMOND, M. 1995. The same esterase B1 haplotype is amplified in insecticide-resistant mosquitoes of the Culex pipiens complex from the Americas 
and China. Heredity, 74, 339-345.

RAO, D. R., MANI, T. R., RAJENDRAN, R., JOSEPH, A. S., GAJANA, A. AND REUBEN, R. 1995. Development of a high level of resistance to Bacillus sphaericus in a field population of Culex quinquefasciatus from Kochi, India. J. Am. Mosq. Contr. Assoc., 11, 1-5.

RAYMOND, M. AND MARQUINE, M. 1994. Evolution of insecticide resistance in Culex pipiens populations: the Corsican paradox. J. Evol. Biol., 7, 315-337.

RAYMOND, M. AND ROUSSET, F. 1995. GENEPOP (Version. 1.2): population genetics software for exact tests and ecumenicism. J. Hered., 86, 248-249.

RAYMOND, M., FOURNIER, D., BRIDE, J.-M., CUANY, A., BERGÉ, J., MAGNIN, M. AND PASTEUR, N. 1986. Identification of resistance mechanisms in Culex pipiens (Diptera: Culicidae) from southern France: insensitive acetylcholinesterase and detoxifying oxidases. J. Econ. Entomol., 79, 1452-1458.

RAYMOND, M., PASTEUR, N., GEORGHIOU, G. P., MELlon, R. B., WIRTH, M. C. AND HAWLEY, M. K. 1987. Detoxification esterases new to California, USA, in organophosphateresistant Culex quinquefasciatus (Diptera: Culicidae). $J$. Med. Entomol., 24, 24-27.

RAYMOND, M., BEYSSAT-ARNAOUTY, V., SIVASUBRAMANIAN, N., MOUCHÈs, C., GEORGHIOU, G. P. AND PASTEUR, N. 1989. Diversity of the amplification of various esterases $\mathrm{B}$ responsible for organophosphate resistance in Culex mosquitoes. Biochem. Genet., 27, 417-423.

RAYMOND, M., CALlaghan, A., FORT, P. AND PASTEUR, N. 1991. Worldwide migration of amplified insecticide resistance genes in mosquitoes. Nature, 350, 151-153.

RAYMOND, M., POULIN, E., BOIROUX, V., DUPONT, E. AND PASTEUR, N. 1993. Stability of insecticide resistance due to amplification of esterase genes in Culex pipiens. Heredity, 70, 301-307.

RAYMOND, M., QIAO, C. L. AND CALlAGHAN, A. 1995. Esterase polymorphism in insecticide susceptible populations of the mosquito Culex pipiens. Genet. Res., 67, 19-26.

RILEY, M. A., KAPLAN, S. R. AND VEUILlE, M. 1992. Nucleotide polymorphism at the xanthine dehydrogenase locus in Drosophila pseudoobscura. Mol. Biol. Evol., 9, 56-69. RIVET, Y., MARQUINE, M. AND RAYMOND, M. 1993. French mosquito populations invaded by A2-B2 esterases causing insecticide resistance. Biol. J. Linn. Soc., 49, 249-255.

ROOKER, S., GUILlEMAUd, T., BERGÉ, J., PASTEUR, N. AND RAYMOND, M. 1996. Coamplification of A and B esterase genes as a single unit in the mosquito Culex pipiens. Heredity, 77, 555-561.

ROUSSET, F., BOUCHON, D., PINTUREAU, B., JUCHAUlt, P. AND SOLIGNAC, M. 1992. Wolbachia endosymbionts responsible for various alterations of sexuality in arthropods. Proc. $R$. Soc. B, 250, 91-98.

SCHAEFFER, S. AND MILLER, E. L. 1992. Molecular population genetics of an electrophoretically monomorphic protein in the alcohol dehydrogenase region of Drosophila pseudoobscura. Genetics, 132, 163-178.

vaughan, A. AND hemingway, J. 1995. Mosquito carboxylesterase Esta2 ${ }^{1}$ (A2). J. Biol. Chem., 270, 17044-17049.

VAUGHAN, A., RODRIGUEZ, M. AND HEMINGWAY, J. 1995. The independent gene amplification of electrophoretically indistinguishable B esterases from the insecticideresistant mosquito Culex quinquefasciatus. Biochem. J., 305, 651-658.

VEUILLE, M. AND KING, L. M. 1995. Molecular basis of polymorphism at the esterase-5B locus in Drosophila pseudoobscura. Genetics, 141, 255-262.

WIRTH, M. AND GEORghiou, G. P. 1996. Organophosphate resistance in Culex pipiens from Cyprus. J. Mosq. Contr. Assoc., 12, 112-118.

WIRTH, M., MARQUINE, M., GEORGHIOU, G. P. AND PASTEUR, N. 1990. Esterases A2 and B2 in Culex quiquefasciatus (Diptera: Culicidae): role in organophosphate resistance and linkage studies. J. Econ. Entomol., 27, 202-206.

XU, J., QU, F. AND LIU, w. 1994. Diversity of amplified esterase B genes responsible for organophosphate resistance in Culex quinquefasciatus from China. J. Med. Coll. PLA, 9, 20-23. 